\title{
GP revalidation in the UK: what lessons can be learned from the Dutch system?
}

What is new regarding revalidation in Britain? Sir Liam Donaldson's long awaited and recently published report Medical Revalidation: Principles and Next Steps has provided some clarity. ${ }^{1}$ The new regulatory system will be introduced from spring 2009. What are the key principles? Revalidation will consist of two strands: relicensure and recertification. The easiest-to-grasp term seems to be relicensure: all UK doctors will receive a licence to practice medicine that will need to be renewed every 5 years. The main aim is to ensure that they work according to Good Medical Practice. ${ }^{2}$ It will mainly be a local process and the key assessment tool will be the familiar annual appraisal, albeit in a more standardised format, with elements like a 'Good Medical Practice Module' and patient and colleague feedback questionnaires. ${ }^{1,2}$

More complex seems the issue of recertification. This will be applicable to doctors who are registered as a specialist or as a GP. These doctors will need to recertify every 5 years. The royal colleges will set the standards. The report is rather vague regarding how exactly recertification will work. It mentions that evidence should be drawn from a range of sources and activities and that recertification should not depend on one single 'big day' assessment. But what does this mean? Fortunately for GPs the Royal College of General Practitioners (RCGP) have recently released their Good Medical Practice for GPs. ${ }^{3}$

This extensive 72-page document sets explicit standards for recertification for GPs, using familiar headings like 'Good Clinical Care', 'Maintaining Good Medical Practice', 'Relationships with patients', and 'Working with colleagues'. Both the exemplary and unacceptable GP are described, making it more clear what will be expected. ${ }^{1,3}$

Even so at this stage the concept of recertification is theoretical and as such various questions remain. How will recertification work in practice? Or, what will happen to doctors who fail? From that point of view it may be interesting to look at the wellestablished Dutch GP recertification system and to see whether lessons can be learned.

In the Netherlands 'Herregistratie' (recertification) was introduced in 2001. The principles are very simple: for GPs to remain registered they need to work as a GP, they need to prove that they are up to date, and they need to provide out-of-hours care. In the Netherlands out-of-hours care is seen as an integral part of general practice, hence this requirement. In practice this means that every 5 years the GP needs to have worked at least $40 \%$ of the time in general practice, needs to show at least 200 hours of accredited training, and should have done at least 10 out-of-hours sessions per year. ${ }^{4}$

Does it work? Most Dutch GPs manage to get their recertification. There are no figures in the public domain regarding how many fail, however, frequently in the Dutch medical journals there have been letters from disappointed GPs who have lost their registration. These letters come mainly from older GPs who after decades of practice had stopped doing on calls and as result did not fulfil the criteria. The lack of flexibility regarding accredited training was also often mentioned as a problem area. Activities like audits, significant event analyses, and providing GP training were not accredited, making it more difficult to achieve the required 200 hours. Recently the Dutch College for Accreditation GPs (CvAH) has responded and begun to make some exceptions for older GPs as well as becoming more flexible regarding 'alternative learning experiences', for example, publications in journals are now countable for recertification. ${ }^{4-6}$

What happens to the Dutch GPs who have lost their registration? Until recently the exGPs had to complete the whole 3 years of GP training again to be re-accredited. Obviously this was not very popular. In September 2002 a year's programme was introduced, which if completed successfully, results in recertification. The programme consists of 4 days a week of GP work under supervision and 1 day a week for education or study. During the programme the student receives a salary similar to a third-year GP registrar and education costs are paid for. A paper published in 2007 indicated that a total of 57 ex-GPs had started the programme and 27 of them have been re-registered.?

Are there any implications for the UK recertification? The Dutch system is in place and the principles are clear and simple. The approach is mainly one-dimensional and summative. The RCGP looks at the recertification process from several angles. Although complex, this seems a far more comprehensive approach than the current system in the Netherlands. Good Medical Practice for GPs still needs to be transferred into explicit assessment tools. Considering the Dutch experience it would be wise to ensure that a variety of assessment methods are used, including audit, significant event analysis, reflective diary, and E-modules, and that a degree of flexibility regarding what are acceptable learning experiences exists.

An element of the Dutch system, which could be used for UK recertification, is the short-route training for ex-GPs. This would ensure that resources are not wasted and doctors get another chance to work as a GP, such as after a career break, but also making sure that patients are safe. Obviously it would be even better if the UK system could 'pick up' doctors before they lose their registration, as is hoped for via the annual appraisal.

Finally, and this refers to both countries, the crucial question is unanswered: Does recertification actually improve the quality and safety of care? Research in this area is urgently required.

\section{Henricus GJ van den Heuvel}

\section{REFERENCES}

1. Department of Health. Medical revalidation - principles and next steps: the Report of the Chief Medical Officer for England's Working Group. http://www.dh.gov.uk/en/Publications andstatistics/Publications/PublicationsPolicyAndGuidance/D H_086430 (accessed 5 Aug 2008).

2. General Medical Council. Good Medical Practice (2006) London: GMC, 2006. http://www.gmc-uk.org/guidance/ good_medical_practice/index.asp (accessed 5 Aug 2008).

3. Royal College of General Practitioners. Good Medical Practice for General Practitioners. London: RCGP, 2008. http://www. rcgp.org.uk/PDF/GMP_web.pdf (accessed 5 Aug 2008).

4. College voor Accreditering Huisartsen, Accreditering en Nascholing Huisartsen. [College for Accreditation General Practitioners, Accreditation and Continuing Medical Education General Practitioners].

5. Bremerkamp, $\mathrm{C} \mathrm{Na.} 30$ jaar huisarts nog even gedoogd. [After 30 years as a GP still allowed for a short period of time]. Medisch Contact 2007; 62: 1276.

6. Groeneveld, H. Rotterdamse huisarts vecht verlies registratie aan. [Rotterdam GP fights to revert loss of registration] Medisch Contact 2007; 62: 1277.

7. Kooij, L.Terug als huisarts. [Back as GP]. Medisch Contact 2007; 62 : 1260-1262.

DOI: 10.3399/bjgp08X342110 